\title{
Design on Alcohol Concentration Detector Based on STC89C52
}

\author{
Xiang Fulin ${ }^{1, a}$, Yu Cheng ${ }^{2, b}$ and Shen Xiaolei ${ }^{3, c}$ \\ Wenzhou University, Zhejiang Province, China \\ a1079173093@qq.com, b904675906@qq..com, 'sxy-xing@qq.com
}

Key words: Alcohol concentration detection; STC89C52; MQ3; DS18B20

Abstract. An alcohol concentration detector based on STC89C52 is presented. The detector, adopting a single chip microcomputer, STC89C52, as its controlling unit, collects samples of alcohol concentration via a gas sensor MQ3 and ambient temperature via a temperature sensor DS18B20, displays the results on an LCD, and judges whether drivers are drunk or not according to preset values. Since the detector can test not only the alcohol concentration of drivers, but also the alcohol in the air, and has the function of LCD display and sound light alarm, it is promising to be popularized in daily alcohol test due to its easy-use and reasonable-price.

\section{Introduction}

In recent years, with the development of the social economy, cars come into more and more families and consequently accidents due to drunk driving happen more frequently. The most accurate way to judge whether the driver has drunk or not is the detection of the quantities of alcohol in the driver's blood which can be gotten by detecting blood, breath, saliva and urine. It is obviously impossible that policeman blood the driver while dealing with the accident. But after the accident when the police send the driver to hospital and blood, the result of the detection of the alcohol is not accurate. So the best way is detecting the quantities of alcohol by checking the breath. If the driver has drunk, his behavior will be unusual and the breath will also contain alcohol. It is pointed out by the research that the participant has to do expiration in medium strength for more than 3 seconds after a deep inspiration [1]. The content between the alcohol in the breath coming from lung and the alcohol in blood is shown as follows:

$$
\text { BAC }(\text { in } \mathrm{mg} / \mathrm{L} \text { )=BrAC }(\text { in } \mathrm{mg} / \mathrm{L}) * 2200
$$

Here, BAC denotes blood alcohol concentration in $\mathrm{mg} / \mathrm{L}$, and $\mathrm{BrAC}$, breath alcohol concentration in $\mathrm{mg} / \mathrm{L}$ [2]. The factor of 2200 is different in different countries, for example, the factor in the United States is 2000 while in the Europe is 2100 . And now alcohol-breath testers are used to detect the alcohol of drivers' on field detection in many countries.

\section{Programme Design}

Study Contents Judgment standard for drinking drive is defined by law as follows: Safe driving means the driver driving while the numerical value of his or her blood alcohol concentration is less than $20 \mathrm{mg} / 100 \mathrm{~mL}$, the numerical value of drinking driving is more than $20 \mathrm{mg} / 100 \mathrm{~mL}$ and less than $80 \mathrm{mg} / 100 \mathrm{~mL}$ and the numerical value of drunk driving is more than $80 \mathrm{mg} / 100 \mathrm{~mL}$. And the design on alcohol concentration detector strictly abides by national standards. 
System Design Fig. 1 as follows is the block diagram of the detector. As shown in the figure, the system consists of six parts including MCU Part based on STC89C52, A/D Conversion Part, Alcohol-Sensor Part, Temperature-Sensing Part, LCD Display Part and Alert Part. The Alcohol-Sensor Part obtains the voltage signal by detecting the alcohol in breath and sends it to the A/D Conversion Part. The data after A/D conversion is sent to the MCU Part to process and analyze and then compared with the threshold set in the program to judge whether the tested driver is drunk driving or not. If the data is more than the threshold, the buzzer gives out alarm sound instantly as while as LCD (liquid crystal panel) displays the alcohol-detection, meaning the driver is drunk driving. Otherwise, the buzzer responses nothing and the LCD displays "safe driving". Meanwhile, the environment temperature is obtained by the temperature-sensing part and stored in the register and displayed on LCD controlling by the STC89C52. The reset circuit is used to reset and initial the system to close the buzzer when Alert Part works.

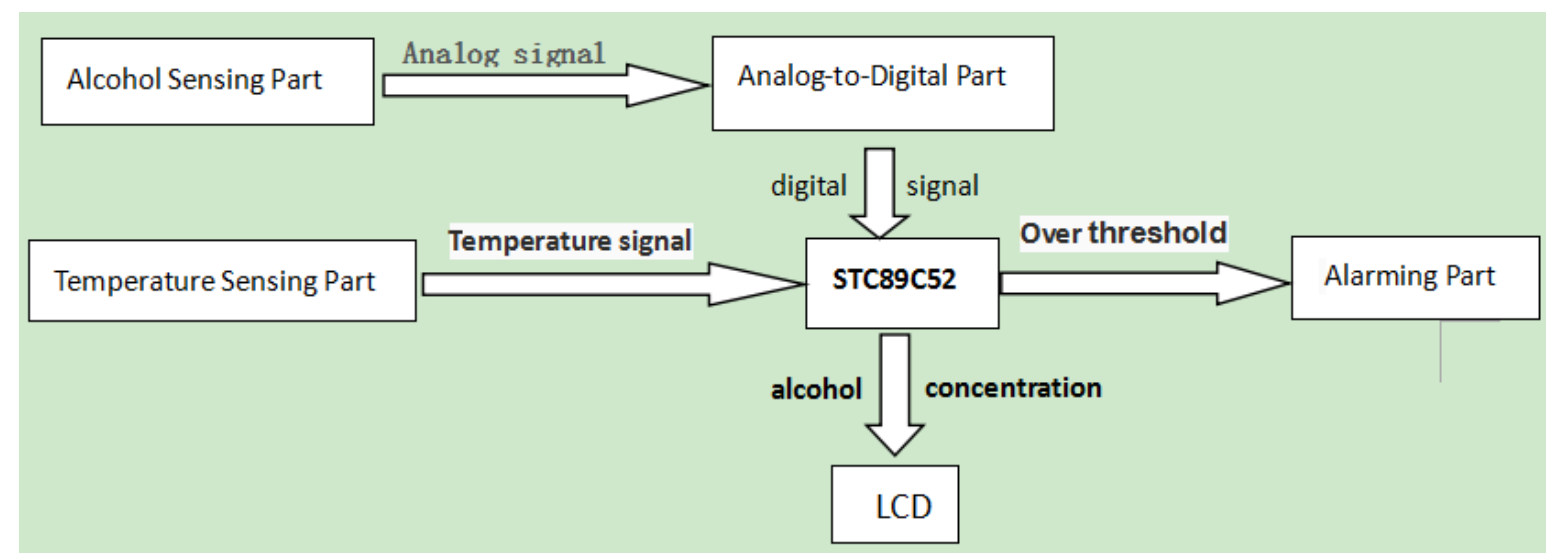

Figure 1: the block Diagram of the Detector

\section{System Realizations}

Components (1) Single Chip Microcomputer STC89C52: An 8-bit microcontroller with an 8k programmable flash memory made by the preparation technics on CMOS and works in Low-Power. Its operating frequency is $11.0592 \mathrm{MHz}$ and the range of its working voltage is from $3.3 \mathrm{~V}$ to $5.5 \mathrm{~V}$.

(2) Analog-to-Digital Converter Chip ADC0809: an 8-bit serial A/ D converter has 8 analog input channels with 8-bit resolution and it also has control terminal for transformation and start-stop. When the working clock is at $640 \mathrm{kHz}$, the time for transformation is $100 \mu$ s and when the clock changes to $500 \mathrm{kHz}$, it needs $130 \mu \mathrm{s}$. It works under $5 \mathrm{~V}$ supply and the range of the analog signal is between $0 \mathrm{v}$ to $5 \mathrm{v}$ without calibration for zero and full scale. Its operating temperature range is between $-40^{\circ} \mathrm{C}$ to $+85^{\circ} \mathrm{C}$, and its power consumption is around $6.2 \mathrm{~mW}$. It operates at frequency of $1 \mathrm{MHz}$ with sampling precision of $5 / 256 \mathrm{~V}$ and quantified digital voltage up to 256 .

(3) Buzzer: an integrated structural electronic acoustic working on a DC voltage and it alarms at a frequency between $1.5 \mathrm{kHz}$ to $2.5 \mathrm{kHz}$.

(4) Display LCD1602: It can show characters and numerics at two lines and each line can display 16 letters. And it can adjust definition by the change of the resistance of the $50 \mathrm{~K}$ sliding rheostat.

(5) Alcohol Sensing MQ3: A kind of gas sensors of which the sensitive material is $\mathrm{SnO} 2$ and its conductivity is very low when it is in clean air. It is a low-cost sensor that can detect different 
alcohol concentrations and has characteristics of high sensitivity, good selectivity for gas, long-term life, high reliability and stability.

MQ3 is fixed in the cavity of stainless steel or plastic by miniature Al2O3, ceramic tubes and sensitive element made by $\mathrm{SnO} 2$-sensitive layer, measuring electrode and heater that applies working conditions for sensitive element. Heating voltage of sensing is $5.0 \mathrm{~V} \pm 0.2 \mathrm{~V}$ and the loop voltage is less than $15 \mathrm{~V}$. The resistance of workload can be adjusted. MQ3 works in standard circuit which contains circuit of heating and circuit of signal output and can reflect the change of the resistance of the sensing accurately and quickly. The change of MQ3 $\left(\mathrm{R}_{\mathrm{S}}\right)$ can be gotten by effective voltage signal $\left(\mathrm{V}_{\mathrm{RL}}\right)$ of the load $\left(\mathrm{R}_{\mathrm{L}}\right)$ which is in series with the sensing indirectly. And the relationship between $R_{S}, R_{L}$, and $V_{R L}$ can be represented as follows:

$\mathrm{RS} / \mathrm{RL}=(\mathrm{VC}-\mathrm{VRL}) / \mathrm{VRL}$

here, $\mathrm{V}_{\mathrm{C}}$ is loop voltage at $10 \mathrm{~V} ; \mathrm{R}_{\mathrm{L}}$ is load of which the resistance can be adjusted within $0.5 \mathrm{~K} \Omega \sim$ $200 \mathrm{~K} \Omega ; \mathrm{U}_{\mathrm{h}}$ is heating voltage of MQ3 at $5 \mathrm{~V}$. When there are alcohol in the environment, MQ3 will detect it and as the concentration of alcohol increases, the electrical conductivity of MQ3 also increases. The standard circuit can change the change of electrical conductivity to its corresponding output voltage $\left(\mathrm{V}_{\mathrm{C}}-\mathrm{V}_{\mathrm{RL}}\right)$ of the same alcohol concentration. And $\mathrm{V}_{\mathrm{C}}-\mathrm{V}_{\mathrm{RL}}$ is sent to the STC89C52 and then the alcohol concentration is displayed [3].

(6) Temperature Sensing DS18B20: It has characteristics of small size, low cost, high ability of interference elimination and high accuracy. The optimal operating voltage range of the device is determined to be within $30-36 \mathrm{~V}$ and the temperature range of measurement is between $-55^{\circ} \mathrm{C}$ to $+125^{\circ} \mathrm{C}$ at unit of degrees Celsius $\left(-67^{\circ} \mathrm{F}\right.$ to $257^{\circ} \mathrm{F}$ at degrees Fahrenheit). The accuracy of the range between $-10^{\circ} \mathrm{C}$ to $+85^{\circ} \mathrm{C}$ is $\pm 0.5^{\circ} \mathrm{C}$. The resolution of the programmable DS18B20 is $9-12$ bit and it just spends $750 \mathrm{~ms}$ to change analog temperature signal to 12-bit number formats.

Hardware The system is controlled by central processing unit based on STC89C52. Analog voltage signal is gotten by Alcohol Sensing Part and sent to Analog-to-Digital part and then the digital signal after AD conversion is sent through P0 (pin0) to STC89C52 which is the control center of the system and the STC89C52 judges whether the tested driver drunk driving or not ${ }^{[4]}$. Temperature Sensing Part is also controlled by STC89C52 and when the tested driver is judged not drunk driving, the temperature signal gotten by temperature sensor DS18B20 is directly sent to STC89C52. LCD Display Part displays the quantitative value of alcohol concentration and temperature from STC89C52.

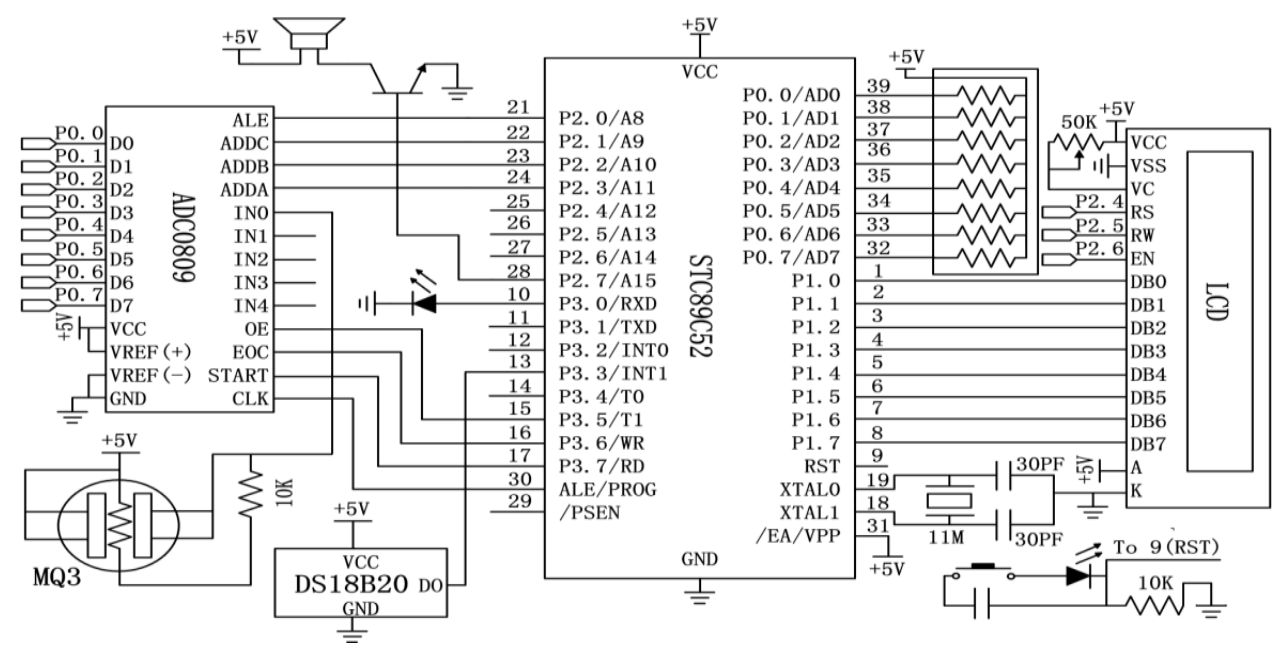

Figure 2: the Schematic Diagram 
System works as follows:

Alcohol Sensing Part and Temperature Sensing Part get analog signals and A/D Conversion Part changes analog signal to digital signal. Finally after processing in STC89C52, the result is displayed the LCD and if the result is over the threshold, the Alarm Part will work.

Software The Flow Chat of Programing is shown as Fig. 3.

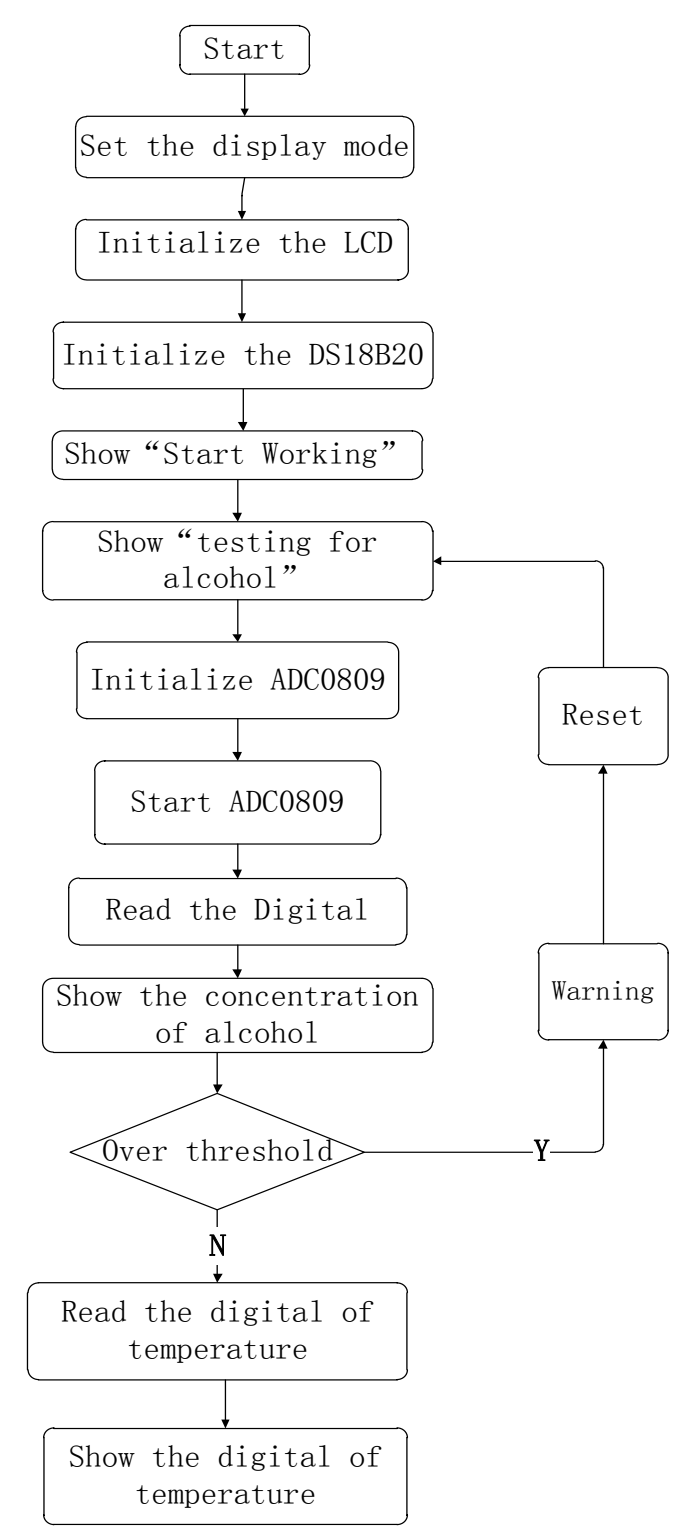

Figure 3: The Flow Chat of Programing

Three Patterns are set up at the beginning of the programing including SAFE DRIVING, DRINK-DRIVING, DRUNK-DRIVING and then LCD, ADC0809 and temperature senor are initiated. Analog voltage signal is gotten by Alcohol Sensing Part and sent to Analog-to-Digital part and then the digital signal changed in Analog-to-Digital part is sent through P0 (pin0) to STC89C52 to judges whether the tested driver drunk driving or not [4]. When the numerical value of alcohol concentration is less than $20 \mathrm{mg} / 100 \mathrm{~mL}$, LCD will display SAFE DRIVING. When the numerical 
value is more than $20 \mathrm{mg} / 100 \mathrm{~mL}$ and less than $80 \mathrm{mg} / 100 \mathrm{~mL}$, LCD will display DRINK-DRIVING. And when the numerical value is more than $80 \mathrm{mg} / 100 \mathrm{~mL}$, LCD will display DRUNK-DRIVING. Besides, if the result is more than $20 \mathrm{mg} / 100 \mathrm{~mL}$, STC $89 \mathrm{C} 52$ will give out a pulse by pin P2.7 to Alarming Part and the buzzer will alarm to give warning. And if the tested is judged safe-driving, temperature-Sensing Part will get the environment temperatures and the temperature will be displayed on LCD.

Results The measured results are shown in Table 1 and Fig. 4.

The standard concentrations show in Table 1 detected by XHM88 which is one of the Alcohol Concentration Detector sold in the market. The concentration of reality1, reality 2 and reality 3 are the results detected in the same alcohol concentration and the same temperature at $27^{\circ} \mathrm{Cas}$ the standard's by Alcohol Concentration Detector which is presented and realized in the paper.

Table1 Concentration of Reality and Standard

\begin{tabular}{|c|c|c|c|c|c|c|}
\hline & $\begin{array}{c}\text { standar } \\
\mathrm{d}\end{array}$ & reality1 & reality2 & reality3 & reality & $\begin{array}{c}\text { temperatur } \\
\mathrm{e}\end{array}$ \\
\hline \multirow{7}{*}{\begin{tabular}{c} 
alcohol/ \\
$\mathrm{mg} / 100$ \\
\cline { 2 - 7 }
\end{tabular}} & 0 & 0.5 & 2.3 & 1.5 & 1.433 & $27^{\circ} \mathrm{C}$ \\
\cline { 2 - 7 } & 10 & 7.8 & 8.9 & 11.1 & 9.267 & $27^{\circ} \mathrm{C}$ \\
\cline { 2 - 7 } & 20 & 17.6 & 21.2 & 19.8 & 19.533 & $27^{\circ} \mathrm{C}$ \\
\cline { 2 - 7 } & 40 & 28.9 & 26.5 & 33.9 & 29.767 & $27^{\circ} \mathrm{C}$ \\
\cline { 2 - 7 } & 50 & 50.9 & 52.0 & 50.8 & 51.233 & $27^{\circ} \mathrm{C}$ \\
\cline { 2 - 7 } & 70 & 62.3 & 63.0 & 56.9 & 60.733 & $27^{\circ} \mathrm{C}$ \\
\hline
\end{tabular}

As shown in table1, the detection of single measurement by Alcohol Concentration Detector designed by us is a little different from by XHM88 but the results of the alcohol concentration are in the same grade. And there is little difference between the concentration in reality and standard when the three concentrations in reality are averaged. The reason to the difference between two concentrations is because the precision of XHM88 is only $10 \mathrm{mg} / 100 \mathrm{ml}$, so each time the tested result can only step on $10 \mathrm{mg} / 100 \mathrm{ml}$. But the precision of alcohol concentration detector presented on this paper is $0.1 \mathrm{mg} / 100 \mathrm{ml}$. So we can only compare two concentrations by the grade of alcohol. It is obvious that two concentrations measured are in good agreement and the design of alcohol concentration detector presented on this paper is in great success. Furthermore, the accuracy of alcohol concentration detector is higher than XHM88 and the tested data is more reliable. 


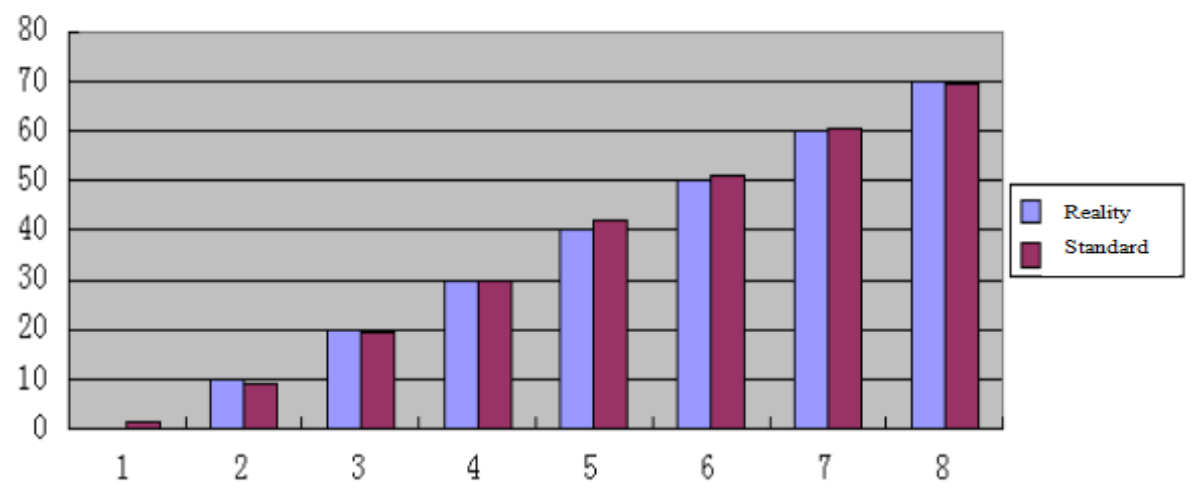

Figure 4: Comparison of the Concentration in Reality and Standard

\section{Conclusions}

An alcohol concentration detector based on STC89C52 is presented. The detector can accurately detect the alcohol concentration by signal acquisition and data disposal through testing breath of tested person. The system designed here uses only external temperature sensor interface to STC89C52 and at next step can be equipped with integrated sensors of humidity, light intensity and pressure. And by changing STC89C52 to the STM32 family, the system can provide a way to realize an intelligent measurement system to monitor alcohol concentration in the car by target recognition and tracking algorithm [5]. In a word, an alcohol concentration detector characterized with a high precision at $0.1 \mathrm{mg} / 100 \mathrm{ml}$, low cost, easily-carried and rapid detection is designed and realized successfully and the new project heralds vast potentials for development and considerable market prospects.

\section{REFERENCES:}

[1]Yue Rui. Advance in the breath alcohol sensor for policeman[J]. Chemical Sensors, 2006,26(3)

[2]Chen Zuhao, Shi Zhiyuan. Alcohol concentration detector for policeman[A]. http://club.1688.com/article/56372110.html, 2011-12.

[3]Han Cheng, Zhang Yan. Just use the single-chip[M]. Bei Jing: POSTS \& TELECOM PRESS, 2008.

[4]Liu Huanping. An access method of ADC0809 and AT89C51[J].Journal of Shijiazhuang Preschool Teachers College, $2002,(02): 52-53$.

[5]Wang Xioadong. Design of vehicle alcohol concentration detector[J].Silicon Valley,2010-06:23. 